\title{
APPLICATION OF LOCAL HYPERBARIC OXYGEN THERAPY WITH USE OF DEVICE LASEROBARIA - $S$ IN THE TREATMENT OF CHRONIC WOUNDS
}

\author{
Aleksander Sieroń ${ }^{1)}$ Jarosław Pasek $^{1,2)}$, Mikołaj Pietrzak ${ }^{1)}$, Grzegorz Cieślar ${ }^{1)}$ \\ 1) Department of Internal Medicine, Angiology and Physical Medicine. School of Medicine with the Division of Dentistry in Zabrze. Medical University of \\ Silesia in Katowice, Poland \\ ${ }^{2)}$ Jan Długosz Academy in Częstochowa. Institute of Physical Education Tourism and Physiotherapy, Częstochowa, Poland
}

\section{ABSTRACT}

For many years now we have been observing a growing number of patients with amputations performed on lower extremities due to chronic wounds occurring as a result of atherosclerotic lesions in peripheral arteries, thromboembolism as well as due to chronic ischaemia in lower extremities. Modern physical medicine is systematically enhancing treatment possibilities for patients with chronic wounds by an introduction of innovative therapeutic devices into clinical practice, which often allow to prevent amputations, accelerate the healing process, and, most of all, alleviate or completely eliminate pain. The article presents the therapeutic mechanism and methodology of one of such methods - local hyperbaric oxygen therapy with the use of a device called LASEROBARIA - S, alongside a description of its therapeutic effects in the case of two patients.

Key words: chronic wounds, physical medicine, local hyperbaric oxygen therapy, LASEROBARIA - S.

ARTICLE INFO

PolHypRes 2016 Vol. 57 Issue 4 pp. 29 - 38

ISSN: 1734-7009 elSSN: 2084-0535

DOI: $10.1515 / \mathrm{phr}-2016-0023$

Pages: 9, figures: 7 , tables: 0

page www of the periodical: www.phr.net.pl

Publisher

Polish Hyperbaric Medicine and Technology Society
Case study article

Submission date: $07.09 .2016 r$.

Acceptance for print: 12.12.2016r. 


\section{INTRODUCTION}

Hyperbaric oxygen therapy (HBO) is a method based on the therapeutic effect of $100 \%$ oxygen or a gas mix with an oxygen content approaching $100 \%$ at a pressure above 1 atmosphere [1]. In the conditions of hyperbaric oxygen therapy the oxygen pressure in the alveolar air is increased, the alveolar-arterial gradient grows and thus, in concord with Henry's law, so does the oxygen diffusion and solubility in the blood plasma. In such conditions, haemoglobin is practically completely desaturated with oxygen (except for a small amount of physically inactive haemoglobin). Further increase in oxygen transportation may be obtained only through an increase of its solubility in blood plasma $[1,2]$.

Breathing with pure oxygen at an atmospheric pressure equal to 1 absolute atmosphere (ATA) causes a tripling of oxygen solubility as compared with breathing with atmospheric air. In response to the pressure of 2-3 ATA (usually applied during hyperbaric oxygenation) the oxygen solubility in blood plasma increases by 14 times [3].

Hyperbaric oxygen, depending on the applied physical parameters, may have both positive and negative effects on the human organism. Positive effects mainly concern the lesions connected with the functioning of the respiratory and circulatory system, as well as processes connected with the healing of chronic wounds. An increase in tissue oxygenation causes an acceleration of fibroblast proliferation, regeneration of ischaemic skin fragments, granulation and epithelialisation of wounds, stimulation of angiogenesis, as well as an improvement in the arterial and venous blood flow in tissues [4].

Currently, based on the results of the thus far conducted randomised and multi-centre clinical trials, the following main indications have been defined regarding a systemic use of hyperbaric oxygen therapy in hyperbaric chambers (acc. to the 7th European Consensus Conference on Hyperbaric Medicine, Lille 2004) [5,6]:

- carbon monooxide poisoning,

- decompression sickness (pressure - usually above 3 ATA and the time of procedures defined acc. to dedicated decompression tables),

- gas embolism,

- bacterial infections (aerobic and anaerobic bacteria),

- acute ischaemia of soft tissues (crush syndrome, transplants at risk of necrosis, reimplantation of parts of lower limbs amputated as a result of an injury),

- slow-healing wounds (infectious complications and diabetic foot syndrome - it is recommended to perform percutaneous oxymetry during patient qualification),

- $\quad$ radiation induced tissue damage: preventive and supportive use following radiotherapy,

- thermal burns.

The negative systemic effects of hyperbaric oxygen therapy mainly result from an incorrect operation of dedicated equipment, setting incorrect treatment parameters, excessively high pressure values (above3 ATA) or a failure to observe of safe operating procedures, thus leading to an increased incidence of ventricular tachyarrhythmias, a significant decrease in heart rate, an occurrence or decompression sickness symptoms and an earache $[1,7]$.

The above described negative impacts of hyperbaric oxygen on a human organism impose numerous contra-indications regarding treatment in single- and multi-place hyperbaric chambers (e.g. pulmonary embolism, hypertension, hypoglycaemia events, reported seizures, presence of a pacemaker and claustrophobia), which may deprive some patients of the possibility to use this form of hyperbaric oxygen therapy, whereas local hyperbaric oxygenation procedures can still be performed in this group of patients due to the absence of the said contra-indications [8].

The treatment of vascular diseases that constitute an etiological factor in chronic wounds mainly consists in prophylaxis (mobility, physical activity, proper nutrition, avoidance of stimulants), pharmacological treatment, and, finally, surgical treatment. For many years chronic wounds therapy has been applied, in concord with the recommendations of the International Advisory Board and the Polish Wound Management Association, the TIME system (tissue debridement, infection control, moisture balance, epidermisation).

This article presents an innovative method supporting the above routine treatment of chronic wounds on the basis of 2 clinical cases, using a local hyperbaric oxygen therapy device LASEROBARIA - S, which significantly improves treatment effectiveness with regard to this pathology as well as diminishes the risk of limb amputation due to complications related to the presence of chronic wounds $[2,9]$.

Local tissue oxygenation improvement is currently becoming a new commonly applied treatment standard with regard to peripheral arterial diseases. Hence, the development of the multifunctional therapeutic device - LASEROBARIA - S developed by Prof. Aleksander Sieroń, Ph.D., M.D. and his team, for the treatment of slow-healing wounds and used to compliment essential treatment (dressings, pharmacotherapy) or surgical treatment is a favourable solution for patients dealing with chronic wounds induced by diabetes, sclerosis and venous insufficiency (fig. 1) [8]. 


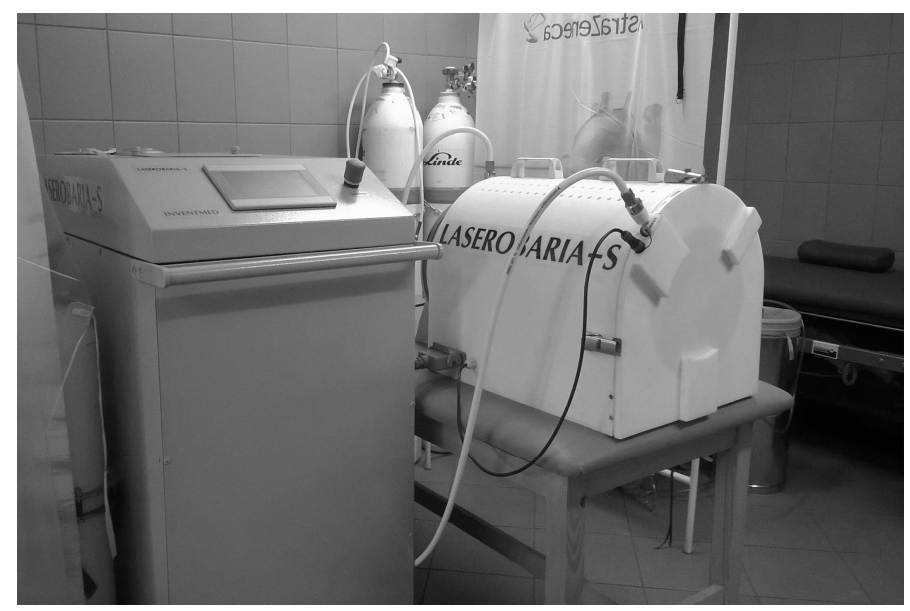

Fig. 1. Multifunctional therapeutic device used in local hyperbaric oxygen therapy - LASEROBARIA - S.

Irrespective of its effects as a local oxygen therapy device, the apparatus enables treatment in the form of a combined therapy, where the simultaneous application of ozone, variable magnetic field and lowenergy light with a suitable configuration of physical parameters causes a synergy effect connected with the intensification of epidermisation, improved nutrition, tissue oxygenation and vascularisation, as well as maintaining wound antisepsis (ozone therapy), which significantly accelerates and improves the healing capacity of a chronic wound $[1,8]$.

The portable LASEROBARIA - S device enables performance of the following procedures: a) hyperbaric oxygen therapy $(1-1.5 \mathrm{mBar} /$ flow of ca. $5 \mathrm{l} / \mathrm{min}$ ),

b) ozone therapy,

c) variable magnetic field therapy (frequency 0.5$100 \mathrm{~Hz}$, induction $15 \mathrm{mT}$ ),

d) low-energy light therapy utilising the red (wavelength of $600-700 \mathrm{~nm}$ ) and ultraviolet (wavelength of 310-410 $\mathrm{nm}$ ) light spectrum.

The device enables simultaneous application of several therapy forms. The required therapeutic programme and parameters are each set on the control panel depending on diagnosis and current clinical condition of the patient (fig. 2). Each procedure lasts approximately 30 minutes, is painless and well-tolerated by patients.

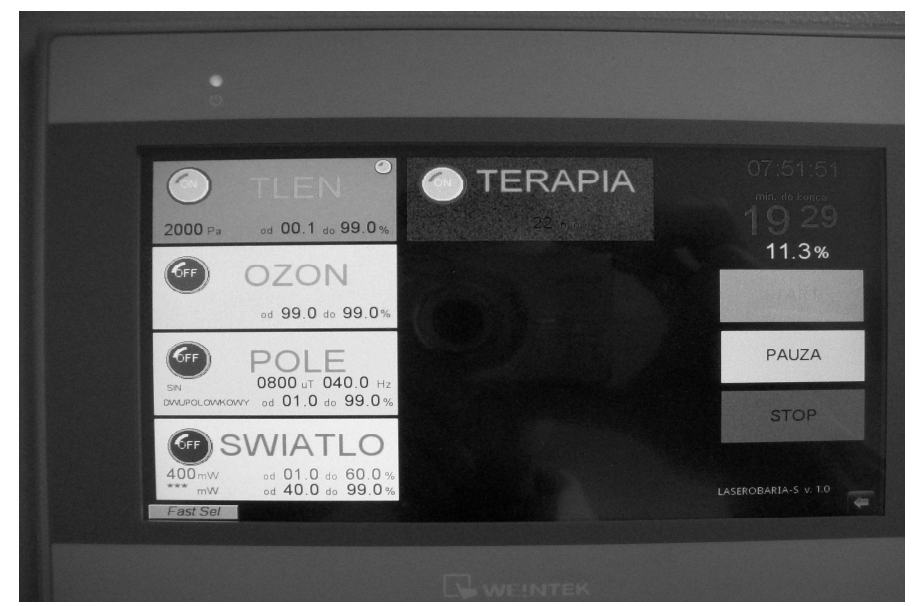

Fig. 2. The control panel of LASEROBARIA $-\mathrm{S}$ device.

Local hyperbaric oxygen therapy consists in placing the patient's limb (upper or lower) inside the applicator - a miniature hyperbaric chamber. Next the chamber is closed with the use of a sealing sleeve and the therapy is commenced following the application of hyperbaric oxygen from a cylinder. Upon treatment completion, the chamber is subject to disinfection (fig. 3). 


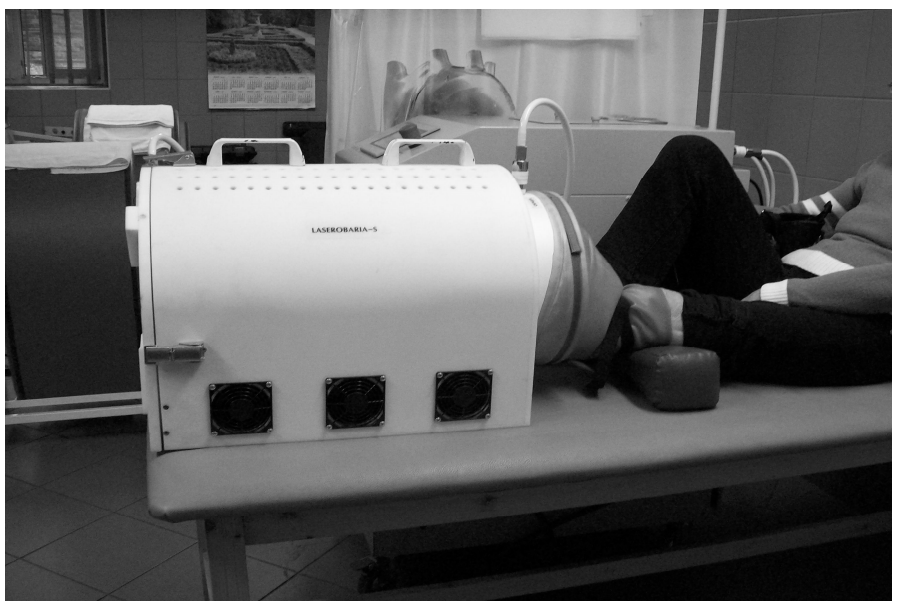

Fig. 3. A procedure with the use of LASEROBARIA - S therapy.

In the case of performing combine therapy, ozone is applied into the interior of the applicator and the limb is additionally subject to the action of a variable magnetic field generated by an electrical coil provided in the applicator's wall as well as light radiation from the red and ultraviolet range emitted by diodes found in the internal applicator surface.

\section{CASE DESCRIPTIONS}

Patient no. 1

A 46-year-old male patient, with an injury in the area of the left heel, resulting of a mining accident that took place in December 2012, was admitted to the Department of Internal Medicine, Angiology and Physical Medicine of Medical University of Silesia in Bytom in 2015 due to an absence of satisfactory results from any of the previously applied treatments, and a high risk of foot amputation. During the admission, the patient reported exacerbated pain in the wound area and difficulties in moving, also a physical examination confirmed the presence of an unhealed wound in the area of the left heel (fig. 4).

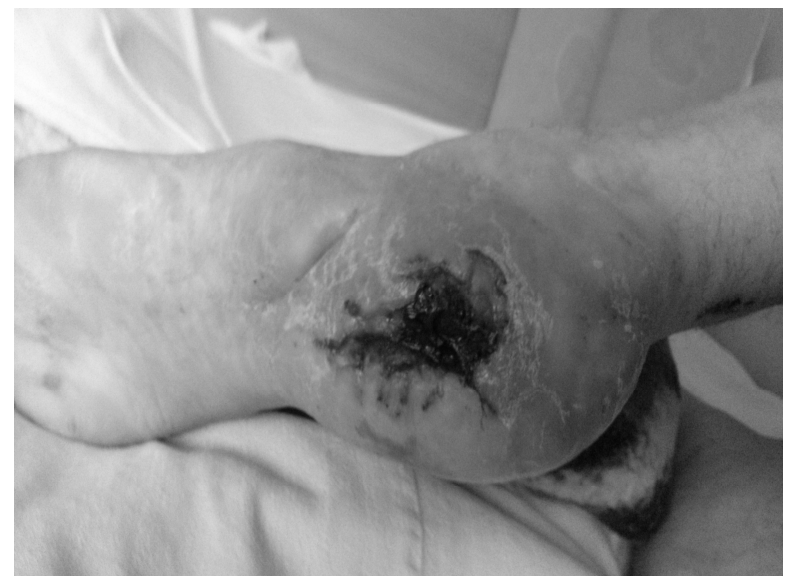

Fig. 4. Local condition at the admission to the Clinic before the commencement of a local hyperbaric oxygen therapy cycle

According to medical records, in the past the patient had undergone treatment in hyperbaric chambers - 200 procedures in total, moreover, two unsuccessful skin transplantation procedures were performed.

During surgical consultation performed at the time of hospitalisation, the wound was cleansed of necrotic tissues, which was followed by the commencement of local hyperbaric oxygen therapy with the use of the LASEROBARIA - S device; this being performed once a day, 5 days a week excluding Saturdays and Sundays, in a series of 15 procedures at 4-week intervals. The duration of a single procedure was 30 minutes. The pressure of the oxygen inside the applicator was equal to 1.5 ATA. Following each procedure, an anti- allergic dressing containing silver was applied on the wound to ensure its antisepsis and mechanical protection. Systematic reduction in the intensity of the inflammatory reaction of the tissues surrounding the wound was observed during the therapy, as well as its gradual alleviation, and at the end of the therapeutic cycle the patient was completely relieved from the previously reported acute pain. The wound was healed completely after 8 months from treatment commencement, and the local condition following the completion of the therapy cycle is presented in fig. 5. 


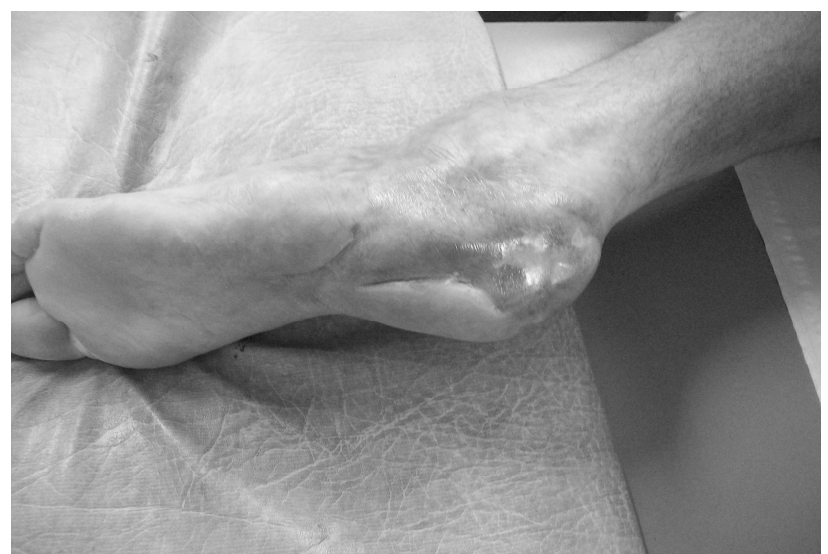

Fig. 5. Local condition upon the completion of an 8-month local hyperbaric oxygen therapy cycle - visible complete healing of the wound in the right heel area.

Patient no. 2

In 2015 a 58-year-old female patient was admitted to the Department of Internal Medicine, Angiology and Physical Medicine of Medical University of Silesia in Bytom with diagnosed chronic inflammation of the lymphatic ducts - this having persisted for three years. A physical examination performed upon admission to hospital confirmed a vast wound covering the internal and external part of the right lower leg above the ankles (fig. 6), with the patient reporting very strong, piercing pain and a tearing and stinging sensation in the wound area.

Fig. 6. Local condition at the admission to the Clinic before the commencement of local hyperbaric oxygen therapy.

During the patient's hospitalisation, an identical hyperbaric oxygen therapy procedure was applied as in the case of the previously described patient, also with the use of the LASEROBARIA $-\mathrm{S}$ device. The treatment was performed once a day, 5 days a week excluding Saturdays and Sundays, in a series of 15 procedures with 4 -week intervals. The duration of a single procedure was 30 minutes. The pressure of the oxygen inside the applicator was equal to 1.5 ATA. Following each procedure, an antiallergic dressing containing silver was applied on the wound to ensure its antisepsis and mechanical protection. 


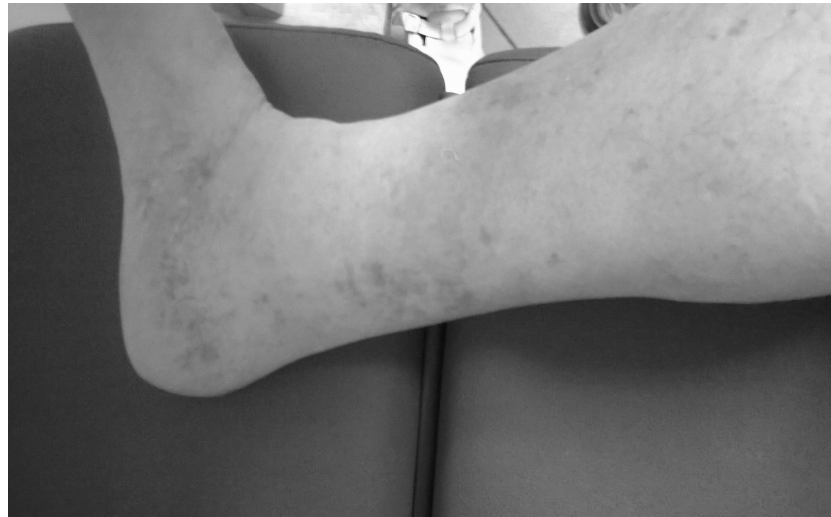

Fig. 7. Local condition upon the completion of an 6-month local hyperbaric oxygen therapy cycle - visible complete healing of the wound in the lower leg area.

Similar to the case described above, a systematic reduction in the intensity of the inflammatory reaction of the tissues surrounding the wound was observed during the therapy, as well as its gradual alleviation, and at the end of the therapeutic cycle the patient was completely relieved from the previously reported acute pain. In this case the wound was healed completely after 6 months from treatment commencement, and the local condition following the completion of the therapy cycle is presented in fig. 7.

\section{DISCUSSION OF THE RESULTS}

Chronic wounds constitute a very serious medical problem which is connected with patients' suffering and substantial costs of the conducted treatment. In many cases the prognoses are bad as healing of a deep and vast wound is extremely difficult if not impossible. The treatment choice mainly depends on wound advancement. The presented cases prove the favourable effects of an early implementation of physical medicine procedures, including local hyperbaric oxygen therapy, which activates a chain of physical, chemical and cellular processes in the damaged tissue, thus leading to a complete healing of the wound $[9,10]$.

The therapeutic usefulness, of local hyperbaric oxygen therapy with the use of the LASEROBARIA $-S$ device in treatment of chronic wounds, is moreover confirmed with clinical trial results where a significant alleviation or even a complete elimination of pain occurring in the majority of patients was observed, as well as a strong anti-inflammatory effect, which in combination with the high effectiveness in wound healing translates into an improvement of the patient's quality of life [11].
It is worth noting that local hyperbaric oxygen procedures are painless and do not require any special preparations - which constitutes a very significant aspect when it comes to encouraging patients to utilise them. Considering the very short list of contra-indications related to the use of local hyperbaric oxygen therapy, and its high medicinal effectiveness, this method may prove to be a valuable complement to classical pharmacological treatment of chronic wounds, and in many complicated cases may prevent the necessity to perform a limb amputation.

\section{Conclusions}

The problem of chronic wounds is very significant as, according to statistical data, it effects approximately 500,000 patients. Any negligence in treating such wounds may lead to very serious complications, and, in the worst case scenario, to limb amputation. Unfortunately, the social awareness in this area is still insufficient. Very often patients seek help too late, when an ulceration and destruction of deep tissues has already occurred, alongside other neurological disorders.

In such advanced cases, hope is sought in an application of new technologies that are the basis of innovative therapeutic methods of physical medicine. Using devices of the highest technical quality, which exhibit a high therapeutic efficiency, while lacking significant undersired side effects, and which at the same time are commonly available, simple to operate, portable and possible to use not only on hospital wards but also in out-patient practice or even in a domestic environment.

\section{BIBLIOGRAPHY}

1. Sieroń A., Cieślar G., Kawecki M. (ed.): An outline of hyperbaric medicine. II edition. $\alpha$-medica press, Bielsko-Biała 2007;

2. Kalani M., Jorneskog G., Naderi N., Lind F., Brismar K.: Hyperbaric oxygen (HBO) therapy in treatment of diabetic foot ulcers. Long-term follow-up. J Diabetes Complications 2002; 16(2): 153-58;

3. Strauss M.B.: Hyperbaric oxygen as an intervention for managing wound hypoxia: its role and usefulness in diabetic foot wounds. Foot Ankle Int. 2005; 26(1): 15-8;

4. Thackham J.A., McElwain D.L., Long R.J.: The use of hyperbaric oxygen therapy to treat chronic wounds: A review. Wound Repair Regen. 2008; 16(3): 321-30;

5. Skeik N., Porten B.R., Isaacson E., Seong J., Klosterman D.L., et al.: Hyperbaric oxygen treatment outcome for different indications from a single center. Ann Vasc Surg. 2015; 29(2): 206-14; 
6. Lebel D, Gortzak Y, Nyska M, Katz T, Atar D et al.: Hyperbaric oxygen therapy for chronic diabetic wounds of the lower limbs-a review of the literature. Harefuah 2007; 146(3): 223-7;

7. Plafki C., Peters P., Almeling M., Welslau W., Busch R.: Complications and side effects of hyperbaric oxygen therapy. Aviat Space Environ Med. 2000; 71(2): 119-24;

8. Sieroń A., Pasek J.: LASEROBARIA - S an innovative device in wound treatment in physical medicine. Rehabil w Prakt. 2016; 4: 68;

9. Knefel G., Kawecki M., Szymańska B., Nowak M., Glik J., et al.: Hyperbaric oxygen therapy as a complement to the surgical treatment of diabetic foot syndrome. Inż Biomed. 2008; 14(1): 47-50;

10. Hunter S, Langemo DK, Anderson J, Hanson D, Thompson P: Hyperbaric oxygen therapy for chronic wounds. Adv Skin Wound Care 2010; 23(3): 116-9;

11. Pasek J., Opara J., Pasek T., Szwejkowski W., Sieron A.: The significance of research on the quality of life in rehabilitation. Fizjoterapia. 2007; 15(3): 3-8.

dr n. o kult. fiz. Jarosław Pasek

Katedra i Oddział Kliniczny Chorób Wewnętrznych,

Angiologii i Medycyny Fizykalnej

Wydział Lekarski z Oddziałem Lekarsko-Dentystycznym w Zabrzu

Śląski Uniwersytet Medyczny w Katowicach

ul. Stefana Batorego 15, 41-902 Bytom

$$
\text { tel: (32) 786-16-30 }
$$

e-mail: jarus_tomus@o2.pl 